\title{
A Study on the Influence of the Audience on the Aesthetic Cognition of the Ballet Swan Lake
}

\author{
Jiongling Chen ${ }^{1, *}$
}

\author{
${ }^{1}$ School of Music and Dance, Shaoguan University, Shaoguan, Guangdong, China \\ *Corresponding author. Email: chenjiongling@163.com
}

\begin{abstract}
The main purpose of this study is to analyze the reasons for the differences in aesthetic cognition between classical ballet and modern ballet Swan Lake. This paper takes the dance of "Four Little Swans" as the research object, takes Aristotle's "six elements of tragedy" as the evaluation element, and uses questionnaire survey and quantitative analysis to study. The results show that among the evaluation elements of the classical version of Swan Lake, the skills of dancers, the melodies of music and the themes deeply rooted in the hearts of the people are all significantly related to the audience's preference for the work, which is also the work of art created by the artist through the three layers of technology, semantics and effect.
\end{abstract}

\section{Keywords: Swan Lake, six elements of tragedy, art communication, aesthetic cognition}

\section{INTRODUCTION}

Swan Lake has always been the classic of the ballet classics since it was created for a hundred years. It has been adapted into many versions and presented on the stage. Its success lies not only in the perfect music and dance but also in different interpretation versions during the repeated iterations such as the "acrobatic version" of the Soldier Acrobatics Troupe of Political Department of Guangzhou Military Region, the "crossdresser version" (men dress as women) of Les Ballets Trockadero de Monte Carlo, the "phantom version" of the Hamburg Ballet (Germany) (also known as "Hamburg version"), the "absurd version" of Mats Ek (1945-) and the "dark version" of Les Ballets de Monte Carlo. It is because of the benchmark of the previous generation of classical dramas that the creators of later generations have to consider how to present a new appearance in different interpretations.

Swan Lake was premiered in Moscow on February 20, 1877 (but it failed to be handed down). On January 15, 1895, the four-act fairy tale ballet Swan Lake directed by Marius Petipa (1818-1910) and Lev Ivanovich Ivanov (1834-1901) was performed successfully in Malinsky Theatre, St. Petersburg. For a century, Swan Lake has always been a symbol of purity, wonderfulness and nobility. The ending of the story has two different versions, namely comedy and tragedy. Accompanied with the sad and beautiful music of Pyotr llyich Tchaikovsky (1840-1893), Swan Lake has become a household name in all classical ballets. In 1995, Matthew Bourne's (1960-) imaginative and conceptual modern ballet Swan Lake was premiered at
Sadler's Wells Theatre in London, UK, and it was also known as "Swan Lake for Men", and then it was immediately labeled as "Swan Lake for Gays". Perhaps, this is not surprising. Bourne's swan is not an elegant dancer in a ballet skirt but a masculine man in feathered trousers with his upper body naked. This may lead to a catastrophic subversion. However, both audience and critics spoke highly of this work. Alastair Macaulay, a dance critic of New York Times had an intimate and indepth conversation with Matthew Bourne and his adventures in the dance. Bourne's swan is not an imitation of female swan but takes classical ballet as a prototype so as to reveal the inherent possibility and show more possibilities for the regulation of traditional culture through this external tension. In other words, to change the tradition requires some reference. Bourne not only used the form of classical ballet but also created his own Swan Lake.

As an iconic representative of the classical ballets, Swan Lake has been performed all over the world for more than 100 years, and it is put on the stage with beautiful choreography and successful music. Although most dance regiments modified the choreography in the 19th century to adapt to the visions of aesthetics or specific choreographer at that time, most versions still followed the details and spirit of the original work. As an art form, classical ballet is based on an ancient and rigorous tradition, which ranges from clothing, toe shoes, every dance step to dancer's specific posture. Gender (female) role is an integral part of these conventions, for art originates from the culture it develops. Since its premiere, the modern version of Swan Lake has been wrongly recognized as "Swan Lake for Gays", although Bourne said publically in the 
early days that it was not homosexual, or homosexual elements were subject to human loneliness and the need for love, which was a bigger emotional and philosophical issue. As a director and choreographer, he recreated the story with a contemporary background correlated to reality. Meanwhile, he used symbolic scenes, lighting, actions and even some humorous techniques to push this "leap" to the height of art.

As a model, the classical ballet Swan Lake is a perfect performance model for others, presenting a specific identity and a specific dance form. In society and classical ballet, it is usually strictly divided according to gender, but Bourne's swans are all performed by men, and the protagonist is also changed from a princess to a prince. The prince is not a hero but a vulnerable and helpless person, which greatly changes the strict convention of gender and deconstructs the ideology and formal structure of classical ballet. In particular, controversial issues, such as homosexual love and Oedipus plot (despite only a part of it), provide ballet with "practical significance" — reflection on human nature. It can be said that Bourne's Swan Lake is also a model connecting on-stage (fiction) and off-stage (reality) and the emotion between dancers and audience. However, this kind of "subversion" is different from the classical version. It also reminds the audience that the concept of "subversion" is not unitary, and its possibilities and contributions will be diverse. Therefore, the main purpose of this paper is to explore and analyze the differences of the audience's aesthetic cognitions and preferences for the classical version of ballet and the modern version of Swan Lake and how the audience can appreciate the work through technical level, semantic level and effect level and what kind of aesthetic experience can be brought to the audience by the works with the same image and different themes.

\section{LITERATURE DISCUSSION}

\section{A. "Six elements of tragedy" of Aristotle}

Aristotle (384-322 B.C.) defined "tragedy" in his On the Art of Poetry (translated by Chen, Z. M. 1996) [1]: "Tragedy, then, is an imitation of an action that is serious, complete, and of a certain magnitude; in language embellished with each kind of artistic ornament, the several kinds being found in separate parts of the play; in the form of action, not of narrative; through pity and fear effecting the proper purgation of these emotions." $\mathrm{He}$ expounded the formation of tragedy in a historical and local way. We can see that tragedy itself is a complex whole rather than a simple individual. Then, he analyzed the definition and discussed the "six elements of tragedy". Specifically, these six elements include: plot, character, thought, diction, melody and spectacle. Aristotle held that plot was the root of tragedy and the soul of tragedy, for the purpose of tragedy was an imitation of "an action that is serious, complete, and of a certain magnitude". In the plot requirements, "serious" is the difference between tragedy and comedy, that is, it must imitate serious events rather than joking events. "Complete" means that the plot of a tragedy should have beginning, development and ending. There should be a reasonable connection and a natural transition among these three parts. "Of a certain magnitude" means that the plot of a tragedy should be neither too short nor too long. In mass culture and literary works, tragedy has become a symbol of "death", that is, it contains the remarkable characteristics of great men/women, regrets and falls of tragedy. On the contrary, tragedy explores the role of audience (viewers) in paying attention to tragic heroes. They enjoy a lofty status in the drama and have some shortcomings in personality. The performance of the plot is mostly complex and depicts human nature. The content is also of great significance. Tragedy is not only about great men but also about small potatoes.

\section{B. Communication mode of artistic creation}

Goldman (2004) [2] proposed that the evaluation of artistic works required a profound understanding on the communication mode between artists and audience. It is not only a demand in the social context but also for understanding the emotional cognition and experience between the creators and the viewers. The process about how an artist expresses artistic creation is called as encode, and the process about how the audience understand the artistic works is called as decode. As far as the formulaic school of communication theory is concerned and in the communication process from the artistic works creation of the artist (sender) to the audience (receiver), the connotation of a successful artistic works should meet three levels: technical level, semantic level and effect level (Lin, C. L., Chen, J. L., Chen, S. J., Lin, R., 2015) [3]. (1) At the technical level, the audience should be able to perceive the artistic works vividly and make the audience see them. (2) At the technical level, the audience should understand the meaning of the artistic works and make the audience understand them. (3) At the effect level, the audience should be able to understand the artistic works and make the audience moved. Through literature review, combining communication, cognitive theory and "six elements of tragedy" of Aristotle. Proposing a communication mode between dance drama artistic creation communication and audience's aesthetic cognition, which is summarized as "cognitive model of ballet art creation", as shown in "Fig. 1", which is the basis elements of the subsequent evaluation framework of aesthetic cognition. 

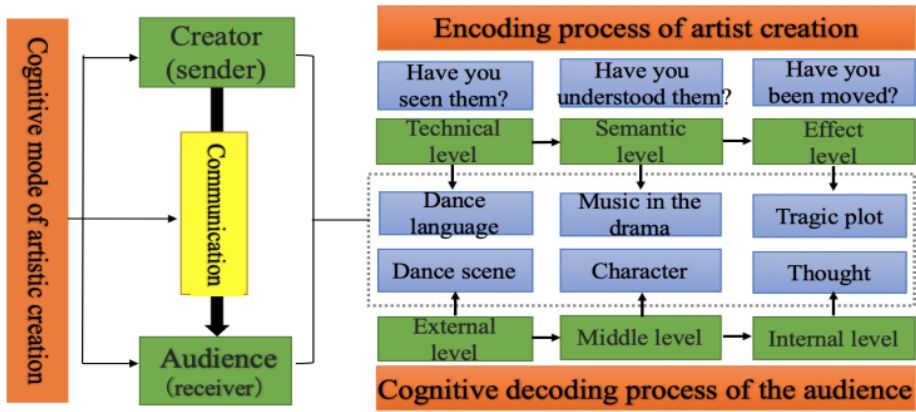

Fig. 1. Cognitive model of ballet art creation.

\section{RESEARCH METHODS}

In this study, "six elements of tragedy" of Aristotle were taken as the attribute for questionnaire design, the audience who watched the dance of "Four Little Swans" in the classical version and modern version of Swan Lake were taken as the subjects. Online questionnaires were sent out, and a total of 191 valid questionnaires were recycled. Among them, 28 (14.7\%)were male and $163(85.3 \%)$ were female; the age groups were divided into: 30 people $(15.7 \%)$ below 20 years old, 111 people $(58.1 \%)$ between $21-30$ years old, 25 people $(13.0 \%)$ between $31-40$ years old, 15 people $(7.9 \%)$ between $41-$ 50 years old and 10 people $(5.3 \%)$ above 51 years old. There were 155 people $(81.2 \%)$ holding a bachelor's degree, $24(12.5 \%)$ holding a master's degree or above and $12(6.3 \%)$ for other education background. There were 80 people $(41.9 \%)$ from dance field, $54(28.3 \%)$ from music field, $6(3.1 \%)$ from other art fields and 51 (26.7\%) from non-art fields. At technical, semantic and effect levels, dance language, dance scene, music in the drama, character, tragic plot and thought were the evaluation factors. In addition, the overall scores of innovation and creativity and preference for the work were added for designing the questionnaire, and the Likert scale ( 1 is the lowest and 5 is the highest) is used for questionnaire survey (questionnaire URL: https://www.wjx.cn/jq/40361348.aspx).

\section{RESEARCH RESULTS}

\section{A. Analyses of validity and reliability}

The audience's decoding of the dance of "Four Little Swans" needed to be studied according to the evaluation framework. Combined with 6 attributes and 12 key factors in the evaluation framework, 28 questions were proposed to evaluate the overall impression of the performance. It could be divided into three categories according to technical level, semantic level and effect level. In particular, Questions 5-8 (1922) were based on attribute of dance language and dance scene, Questions 9-12 (23-26) were based on music and characters in the drama, Questions 13-16 (27-30) were based on tragic plot and thought, and Questions 17-18 (31-32) were the evaluation of the overall dance. That was, the intensity of innovation and creativity and the preference of the work. According to "Table I", the overall reliability of the observation questionnaire was analyzed. The reliability coefficient of the "classical version" Cronbach $\alpha$ was .940 , the corrected total correlation was from .622 to .817 , and " $\alpha$ coefficient after deletion" case was from .931 to .939. The reliability coefficient of the "modern version" Cronbach $\alpha$ was .932, the corrected total correlation situation was from .549 to .849 , and " $\alpha$ coefficient after deletion" was from .921 to .932. Therefore, the reliability of the research data was very high.

TABLE I. EVALUATION FRAMEWORK OF AESTHETIC COGNITION OF "FOUR LitTLE SWANS" IN SWAN LAKE

\begin{tabular}{|c|c|c|c|c|c|}
\hline \multicolumn{6}{|c|}{ Perception Process } \\
\hline \multicolumn{6}{|c|}{ Artist(Coding) } \\
\hline & \multicolumn{2}{|c|}{ Dance language } & \multicolumn{2}{|c|}{ Dance scene } & \multirow{4}{*}{ External level } \\
\hline \multirow[t]{3}{*}{ Technical level A } & A1-1 & A1-2 & A2-1 & A2-2 & \\
\hline & Graceful movements & Superb technology & Gorgeous clothes & Exquisite dance & \\
\hline & \multicolumn{2}{|c|}{ Music in the drama } & \multicolumn{2}{|c|}{ Character } & \\
\hline \multirow[t]{3}{*}{ Semantic level B } & B1-1 & B $1-2$ & B2-1 & B2-2 & \multirow[t]{2}{*}{ Intermediate level } \\
\hline & Beautiful melody & Happy rhythm & Exquisite emotion & Distinctive personality & \\
\hline & \multicolumn{2}{|c|}{ Tragic plot } & \multicolumn{2}{|c|}{ Thought } & \\
\hline \multirow[t]{2}{*}{ Effect level C } & $\begin{array}{c}\text { C1-1 } \\
\text { The plot is moving }\end{array}$ & $\begin{array}{c}\mathrm{C} 1-2 \\
\text { Stimulate imagination }\end{array}$ & $\begin{array}{c}\text { C2-1 } \\
\text { Win support among } \\
\text { the people }\end{array}$ & $\begin{array}{c}\text { C2-2 } \\
\text { Thought-provoking }\end{array}$ & Internal level \\
\hline & \multicolumn{5}{|c|}{ Audience(Decoding code) } \\
\hline \multicolumn{6}{|c|}{ Aesthetic experience } \\
\hline
\end{tabular}


In order to test the validity analysis of the evaluation framework, the KMO coefficient of the "classical version" was .928 , which had a very high value. The Sig value was .000 , which was significant. The eigenvalue was 7.286, which could explain $60.714 \%$ variation of the preset purposes. The load capacity of each factor was from .685 to .851 , and the commonality was from .469 to .724. The KMO coefficient of the "modern version" was .903 , which had a very high value. The Sig value was .000 , which was significant. The eigenvalue was 6.923 , which could explain $57.693 \%$ variation of the preset purposes. The load capacity of each factor was from 0.610 to .883 , and the commonality was from .372 to .780 .

\section{B. Analysis of key factors}

1) Analysis of average scores of preference and innovation and creativity: As shown in "Table II", the results showed that the audience's preference for the classical version was higher than that of the modern version, while the modern version was more innovative and creative than the classical version.

TABLE II. ANALYSIS TABLE OF THE AVERAGE SCORES OF PREFERENCE AND INNOVATION AND CREATIVITY AVERAGES

\begin{tabular}{ccc}
\hline Version & Mean value of innovation and creativity $(M)$ & Mean value of preference $(M)$ \\
\hline Classical version & 3.81 & 4.09 \\
Modern version & 4.31 & 3.75 \\
\hline
\end{tabular}

2) Analysis of the influence of innovation and creativity on preference: As shown in "Table III", the results showed that the score of innovation and creativity was significantly correlated with the score of preference. In particular, 5 people obtained 1 point in the "classical version", 11 people obtained 2 points, 58 people obtained 3 points, 59 people obtained 4 points, and 58 people obtained 5 points. There were a total of 191 people. There was a significant positive correlation between the score of innovation and creativity and the score of preference $(5$ points $>4$ points $>3$ points $>2$ points $>1$ point). 2 people obtained 1 point in the "modern version" (As the number of people was less than 5 , so this item was not included in the survey), 5 people obtained 2 points, 17 people obtained 3 points, 75 people obtained 4 points, and 92 people obtained 5 points. There were a total of 191 people. There was a significant positive correlation between the score of innovation and creativity and the score of preference ( 5 points $>4$ points $>3$ points $>2$ points).

TABLE III. ANALYSIS TABLE OF THE INFLUENCE OF INNOVATION AND CREATIVITY ON PREFERENCE (ANOVA)

\begin{tabular}{|c|c|c|c|c|c|c|c|}
\hline Version & Functional level & Source & SS & DF & MS & $\mathbf{F}$ & Scheffe \\
\hline \multirow{3}{*}{ Classical version } & \multirow{3}{*}{ Innovation and creativity of works } & Between Groups & 81.566 & 4 & 20.392 & \multirow{3}{*}{$51.310^{* * *}$} & \multirow{3}{*}{$5>4>3>2>1$} \\
\hline & & Within Groups & 73.920 & 186 & .397 & & \\
\hline & & Total & 155.487 & 190 & & & \\
\hline \multirow{3}{*}{ Modern version } & \multirow{3}{*}{ Innovation and creativity of works } & Between Groups & 46.304 & 4 & 11.576 & \multirow{3}{*}{$18.701 * * *$} & \multirow{3}{*}{$5>4>3>2$} \\
\hline & & Within Groups & 115.131 & 186 & .619 & & \\
\hline & & Total & 161.435 & 190 & & & \\
\hline
\end{tabular}

3) Analysis of influence factors of preference: As shown in "Table IV" and according to the multiple regression analysis in the table below, the correlation coefficient $\mathrm{R}$ between the overall prediction variable and the dependent variable in the classical version was .818. The explained variance of 12 predictive variables v.s. "dance preference" was $66.9 \%$, and the F value was 30.024 and reached the significant level of .001. In particular, the most important significant prediction variables were as follows: The $\beta$ value of "the dancer is skilled" was .293, reaching the significant level of .001 . The $\beta$ value of "the melody is pleasant" was .211 , reaching a significant level of .01 , and the $\beta$ value of "the theme enjoys popular support" was .221, reaching a significant level of .01. The correlation coefficient $\mathrm{R}$ between the overall prediction variable and the dependent variable in the modern version was .769. The explained variance of 12 predictive variables v.s. "dance preference" was $59.1 \%$, and the $\mathrm{F}$ value was 19.671 and reached the significant level of .001. In particular, the most important significant prediction variable was as follows: The $\beta$ value of "the dancer's movements are graceful" was .149 , reaching a significant level of .05 . 
TABLE IV. REGRESSION ANALYSIS TABLE OF INFLUENCE FACTORS OF PREFERENCE

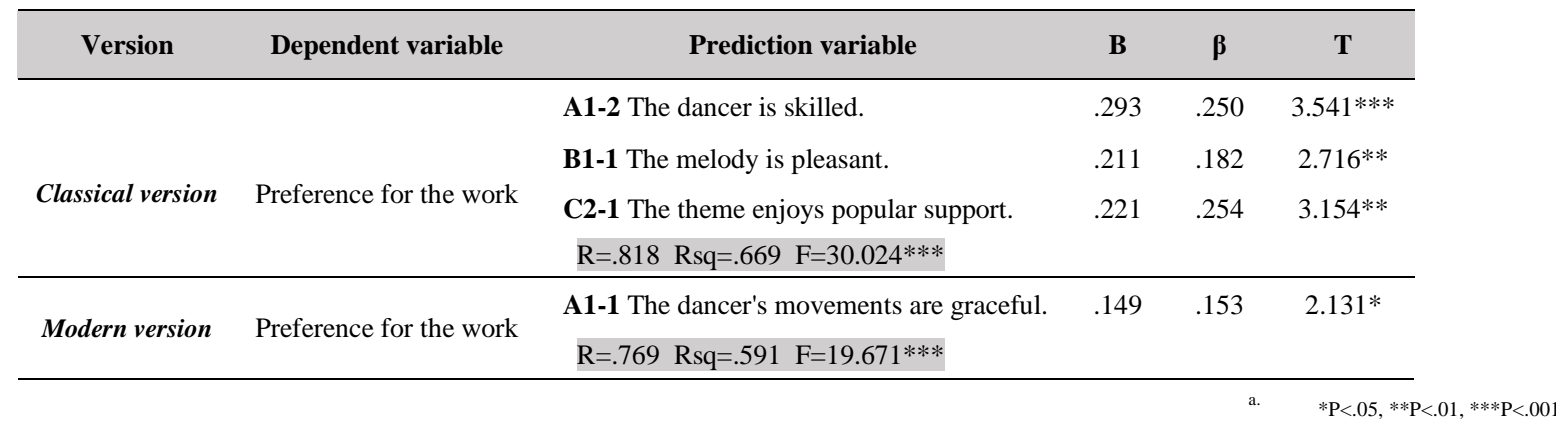

As shown in "Table V", it could be seen by comparing the mean values of 4 attributes which were significantly correlated to the results that the score of the classical version was higher than that of the modern version. It could be seen by ranking the mean values of 12 influencing attributes of the two versions that 3 attributes which were significantly correlated to the preference of the classical version ranked the top five positions. This indicated that the audience had a high recognition for these three attributes. 1 attribute which was significantly correlated to the preference of the modern version ranked the $11^{\text {th }}$ position, indicating that the audience had a low recognition for this attribute.

TABLE V. COMPARISON OF THE MEAN VALUES OF 12 ATTRIBUTES

\begin{tabular}{ccccc}
\hline & $\begin{array}{c}\text { A1-2 } \\
\text { The dancer is } \\
\text { skilled. }\end{array}$ & $\begin{array}{c}\text { A1-1 } \\
\text { The dancer's movements } \\
\text { are graceful. }\end{array}$ & $\begin{array}{c}\text { B1-1 } \\
\text { The melody is } \\
\text { pleasant. }\end{array}$ & $\begin{array}{c}\text { C2-1 } \\
\text { The theme enjoys } \\
\text { popular support. }\end{array}$ \\
\hline Classical version & 4.29 & 4.26 & 4.42 & 4.06 \\
Score ranking & 3 & 4 & 2 & 5 \\
\hline Modern version & 4.05 & 3.50 & 4.16 & 3.81 \\
Score ranking & 5 & 11 & 3 & 7 \\
\hline
\end{tabular}

\section{Relationship between subjects' backgrounds and cognitive factors}

1) Influence of gender on cognitive factors: In this study, 28 male and 163 female subjects were selected and tested according to each dimension. The independent sample t-test was used to analyze and check whether there was any significant difference in gender between the classical version and the modern version. In terms of "the stage art design is delicate", male subjects obtained a score of 3.39 and female subjects obtained a score of 3.63. In terms of "the character emotion is expressed exquisitely", male subjects obtained a score of 3.61 and female subjects obtained a score of 3.78. As shown in "Table VI", the score of women was higher than that of men.

TABLE VI. TABLE OF THE DIFFERENCES OF THE SUBJECTS (MALE/FEMALE) IN ATTRIBUTE COGNITION

\begin{tabular}{|c|c|c|c|c|c|c|c|}
\hline Version & Functional level & Gender & $\mathbf{N}$ & $\mathbf{M}$ & SD & $\mathbf{T}$ & Scheffé \\
\hline \multirow{4}{*}{ Modern version } & \multirow{2}{*}{$\begin{array}{l}\mathbf{A 2 - 2} \\
\text { The stage art design is delicate. }\end{array}$} & Male & 28 & 3.39 & 1.286 & \multirow[t]{2}{*}{$-.942 *$} & \multirow[t]{2}{*}{ Female $>$ male } \\
\hline & & Female & 163 & 3.63 & .929 & & \\
\hline & \multirow{2}{*}{$\begin{array}{l}\text { B2-1 } \\
\text { The character emotion is expressed exquisitely. }\end{array}$} & Male & 28 & 3.61 & 1.197 & \multirow{2}{*}{$-.728 *$} & \multirow{2}{*}{ Female $>$ male } \\
\hline & & Female & 163 & 3.78 & .868 & & \\
\hline
\end{tabular}

As the gender ratio of the subjects was uneven and women were more than men, it could be seen from the selection influence analysis of gender differences showed that 3 attributes affecting the preference for classical version and 1 attribute affecting the preference 
for modern version were not significantly affected by gender.

2) Influence of age, educational background and professional background on cognitive factors: After variance difference was tested, no significant difference was found in age and educational background, but it was significant in professional background. The samples included 80 people from dance field, 54 from music field, 6 from other art fields and 51 from non-art fields. According to the ANOVA analysis of independent samples, there was a significant difference in the attribute evaluation of "characters with distinct personality" in the classical version, and the scores of dance, music, other art and non-art fields were 4.04, $3.80,3.83$ and 3.49 respectively; there was a significant difference in the attribute evaluation of "innovation and creativity", and the scores of dance, music, other art and non-art fields were 4.00, 3.89, 3.33 and 3.47 respectively; there was a significant difference in the attribute evaluation of "preference for the work", and the scores of dance, music, other art and non-art fields were $3.78,3.52,2.50$ and 3.53 respectively. After the different test, the $\mathrm{F}$ value was $3.663^{*}$.

TABLE VII. TABLE OF THE ATTRIBUTE COGNITION DIFFERENCES OF THE SUBJECTS (WITH OR WITHOUT THE DANCE OR ART BACKGROUND)

\begin{tabular}{|c|c|c|c|c|c|c|c|}
\hline Version & Functional level & Source & SS & DF & MS & $\mathbf{F}$ & Scheffé \\
\hline \multirow{9}{*}{ Classical version } & \multirow{3}{*}{$\begin{array}{c}\text { B2-2 } \\
\text { Characters with distinct personality }\end{array}$} & Between Groups & 9.361 & 3 & 3.120 & \multirow{3}{*}{$3.051 *$} & \multirow{3}{*}{$1>4$} \\
\hline & & Within Groups & 191.225 & 187 & 1.023 & & \\
\hline & & Total & 200.586 & 190 & & & \\
\hline & \multirow{3}{*}{ Innovation and creativity } & Between Groups & 10.460 & 3 & 3.487 & \multirow{3}{*}{$3.480^{*}$} & \multirow{6}{*}{$1>4$} \\
\hline & & Within Groups & 187.373 & 187 & 1.002 & & \\
\hline & & Total & 197.832 & 190 & & & \\
\hline & \multirow{3}{*}{ Preference for the work } & Between Groups & 7.862 & 3 & 2.621 & \multirow{3}{*}{$3.320 *$} & \\
\hline & & Within Groups & 147.625 & 187 & .789 & & \\
\hline & & Total & 155.487 & 190 & & & \\
\hline \multirow{3}{*}{ Modern version } & \multirow{3}{*}{$\begin{array}{c}\text { A2-2 } \\
\text { The stage art design is delicate. }\end{array}$} & Between Groups & 10.321 & 3 & 3.440 & \multirow{3}{*}{$3.663^{*}$} & \multirow{3}{*}{$1>2$} \\
\hline & & Within Groups & 175.637 & 187 & .939 & & \\
\hline & & Total & 185.958 & 190 & & & \\
\hline
\end{tabular}

\section{CONCLUSION}

Why are some ballets particularly attractive and popular? What are the influence factors? At the stage of creation and design, the director should know how to apply these factors to make the audience feel and understand the ideas conveyed through the works. For the audience, apart from aesthetic experience or absorption of new knowledge, they need to obtain enrichment and satisfaction in spiritual and sensory experience. Therefore, we must focus on understanding the audience's real feelings after appreciation so as to achieve optimal presentation. Using "six elements of tragedy" of Aristotle to help establish the above model, it is effective to explore the audience's cognition for "Four Little Swans" in Swan Lake, and the research results reflect the different aesthetic cognition of the audience for the two versions. The results are as follows:

- From the analysis of preference and the mean value of innovation and creativity and the influence of innovation and creativity on preference, it can be seen that there is a significant positive correlation between preference and innovation and creativity, but the works that are more popular among the audience and considered by the audience to be more innovative and creative are not the same. It can be seen that in addition to innovation and creativity, there are other factors affecting the preference for the work. As Nietzsche (1996) [4] said, "The symbol of originality is not to discover the new things but treat the old, familiar, seen but ignored things as the new ones". Therefore, the innovation of dance should be integrated with the regression of dance.

- From the influence factors of preference, it can be seen that "the dancer is skilled", "the melody is pleasant" and "the theme enjoys popular support" in the classical version, and "the dancer's movements are graceful" in the modern version significantly affects the audience's 
preference. Among them, the "the dancer is skilled" in the classical version belongs to the technical level, "the melody is pleasant" belongs to the semantic level, and "the theme enjoys popular support" belongs to the effect level, showing the three levels of artistic works created by artists. The aesthetic experience is achieved after skill performance. The two attributes of "the dancer is skilled" and "the dancer's movements are graceful" belong to the technical level, and both of them have a significant influence on the preference for dance. It can be seen that this level has a more obvious influence on the audience's preference than the other two levels. It can be seen that the performer's expression at the technical level has attracted the attention of the audience. Human is the carrier of beauty. As John Martin (translated by $\mathrm{Ou}, \mathrm{J}$. P.1994) [8] said, "Human movement is indeed the essence of life...Besides its most obvious movement function, action is the most active medium of expression and cognition. Dancers use their movements to express their thoughts, while the audiences use the action to understand the thoughts." Action has its own meaning and thought.

- There are some differences in the cognition of dance between different genders. There are significant differences between "the stage art design is delicate" and "the character emotion is expressed exquisitely" in the modern version. The evaluation of women is significantly higher than that of men, and women pay more attention to stage art and emotional expression of characters than men. In the modern version, "Four Little Swans" are not presented in the form of collective dance, but each little swan has its own personality which is clumsy, aggressive and sensitive. In the stage art design, many elements are skillfully integrated, which can bring more abundant visual senses.

- Different professional backgrounds have significantly different cognitions for dance. In the evaluation of the attributes of "characters with distinct personality" and "innovation and creativity" in the classical version and "the stage art design is delicate" in the modern version, professional dance background has higher evaluation, and there is a significant difference. Professional dancers have a higher standard for professional cognition of these three attributes. There are different concepts in the process of performance art creation and presentation. In terms of the evaluation of "preference for the work" in the classical version, those with other artistic backgrounds give higher evaluations than those with dance, music and non-art backgrounds, which showed that the subjects with these three backgrounds had a stricter evaluation standard for this attribute.

\section{References}

[1] Aristotle, "Poetics," Chen, Z. M, Trans. Beijing: The Commercial Press, 1996, pp. 63.

[2] Goldman, A., "The Blackwell guide to aesthetics," Evaluating art, In P. Kivy, Eds. Malden, MA: Blackwell Publishing, 2004, pp.93-108.

[3] Lin, C. L., Chen, J. L., Chen, S. J., \& Lin, R, The cognition of turning poetry into painting, Journal of US-China Education Review B, vol.5(8). 2015, pp. 471-487.

[4] Nietzsche, F, "Human, all too human: A book for free spirits," M. Faber \& S. Lehmann, Trans. Cambridge, England: Cambridge University Press, 1996.

[5] Alastair Macaulay, Matthew Bourne, "Matthew Bourne and His Adventures in Dance: Conversations with Alastair Macaulay," London: Faber and Faber,2011.

[6] Carter, Alexandra, "Rethinking dance history: a reader (Alastair Macaulay. Matthew Bourne, dance history and Swan Lake)," London, New York: Routledge. 2004, pp.157-169.

[7] Juhasz, S., Queer Swans: Those Fabulous Avians in the Swan LakeS of Les Ballets Trockadero and Matthew Bourne, Dance Chronicle, vol.31(1), 2008, pp.54-83.

[8] John Martin, "The introduction to dance," Ou, J. P. Trans. Beijing: Culture and Art Publishing House, 1994.

[9] Kant, I., "Critique of the power of judgment," P. Guyer \& E. Matthews, Trans. Cambridge, England: Cambridge University Press. 2000. (Original work published 1790)

[10] Lin, R. T., \& Lee, S. M., "Poetic and pictorial splendor," New Taipei City: National Taiwan University of Arts, 2015

[11] Fang, W. T., Gao, Y.J., \& Tseng, C. H., Lin, P. H., A Study on Audience Perception of Aesthetic Experience in Dance Performance, Journal of Design, vol. 23(3), 2018, pp. 23-46.

[12] Zhu, L. R., "Selected works of modern western art aesthetics: Dance aesthetics," Taipei: Hongye culture, 1994. 